\title{
Article \\ Influence of Ball Bearing Size on the Flight and Damage Characteristics of Blast-Driven Ball Bearings ${ }^{\dagger}$
}

\author{
Genevieve S. Langdon ${ }^{1,2, *(\mathbb{D})}$, Ruixuan $\mathrm{Qi}^{2}$, Trevor J. Cloete ${ }^{2}$ and Steeve Chung Kim Yuen ${ }^{2}(\mathbb{D}$ \\ 1 Department of Civil and Structural Engineering, University of Sheffield, Sheffield S1 3JD, UK \\ 2 Blast and Impact Survivability Research Unit (BISRU), Department of Mechanical Engineering, University of \\ Cape Town, Cape Town 7700, South Africa; qxxrui001@myuct.ac.za (R.Q.); trevor.cloete@uct.ac.za (T.J.C.); \\ steeve.chungkimyuen@uct.ac.za (S.C.K.Y.) \\ * Correspondence: genevieve.langdon@sheffield.ac.uk \\ + This paper is an extended version of paper published in the 13th International Conference on the Mechanical \\ and Physical Behaviour of Materials under Dynamic Loading, Madrid, Spain, 20-24 September 2021.
}

check for updates

Citation: Langdon, G.S.; Qi, R.; Cloete, T.J.; Chung Kim Yuen, S Influence of Ball Bearing Size on the Flight and Damage Characteristics of Blast-Driven Ball Bearings. Appl. Sci. 2022, 12, 1133. https://doi.org/ 10.3390/app12031133

Academic Editor: Lina M. López

Received: 23 December 2021

Accepted: 20 January 2022

Published: 21 January 2022

Publisher's Note: MDPI stays neutral with regard to jurisdictional claims in published maps and institutional affiliations.

Copyright: (C) 2022 by the authors. Licensee MDPI, Basel, Switzerland. This article is an open access article distributed under the terms and conditions of the Creative Commons Attribution (CC BY) license (https:// creativecommons.org/licenses/by/ $4.0 /)$.

\begin{abstract}
This paper presents insights into the influence of ball size on the flight characteristics and damage of a ball bearing embedded in a rear detonated cylindrical charge. It includes results from a post-test damage analysis of ball bearings from previously reported experiments. Computational simulations using Ansys Autodyn were used to provide extra information about the velocity variation during flight and the damage sustained by the ball bearings during the blast event. The influence of bearing size (diameter and mass) was investigated using the validated simulation models to extend the dataset beyond the initial experimental work. The peak bearing velocity is influenced by the charge mass to ball bearing mass ratio and the aspect ratio of the charge. Larger ball bearings require extra momentum to accelerate them to higher velocities, but their higher surface area means a greater portion of the explosive charge is involved in transferring kinetic energy to the projectile. Tensile spalling was to be the major damage mechanism within the ball bearings. The charge aspect ratio also influenced the hydrostatic pressure propagation within the ball bearing itself, affecting the location and degree of internal cracking within the bearings. These findings will prove valuable to blast protection engineers considering the effects of embedded projectiles in improvised explosive devices.
\end{abstract}

Keywords: improvised explosive devices; blast loading; deformation; damage; ball bearings

\section{Introduction}

Improvised explosive devices (IEDs) have caused harm to hundreds of thousands of people, with over 170,000 people affected in the last decade (2010-2020) [1]. They are especially damaging and lethal because they are often embedded with solid objects, these being normally readily available items such as ball bearings or nails. These embedded objects become projectiles, causing greater fatality rates, traumatic amputations, and soft tissue injuries from IEDs [2,3].

Much research is being conducted to detect IEDs [4,5] and prevent their detonation [6,7]. Other approaches include improved armour for military targets [8], hardening of large-scale critical civilian infrastructure against large IED attacks [9], and research into the destruction of IEDs in the battlefield arena [7]. Vanderherden et al. [10] report on the extraction of touch DNA and fingerprints from detonated IEDs to facilitate the tracking and prosecution of terrorists. These advances are encouraging, but it is unlikely that they will entirely prevent future detonations of person-borne IEDs used in terror attacks.

Understanding the behaviour of blast-driven ball bearings embedded in explosive charges will aid in the development of blast protection from IEDs. One major challenge in IED research is the huge range of potential IED geometries, sizes, explosion types, and embedded object configurations. Hence, a fundamental understanding of the momentum transfer mechanisms of embedded solid particles from the explosive detonation is needed. 
While there is a large body of literature on cratering damage due to impact, research into blast-induced projectile impacts is focused on fragmentation [11-14], such as that in warhead or blast-driven metal [15]. A limited experimental study on the damage caused by incorporating a foreign object in an explosive charge is available in reference [16]. Kang and Chung Kim Yuen [16] did not measure the velocity of the explosively driven projectiles but analysed the damage distribution in the walls of a surrounding steel cylinder. They used the penetration depth to infer information about the effect of packing pattern.

In recent work by Qi et al. [17], a novel experimental arrangement for gaining fundamental insights into the momentum transfer and flight of a solid insert from a simplified IED was proposed and developed. The experiments and subsequent numerical work focussed on the flight characteristics of a single ball bearing driven by the detonation of a plastic explosive. Cylindrical charges were studied as these were deemed more practical and realistic geometries for IEDs. The effect of charge shape has been shown to be highly influential in the near field, while its influence on peak pressure was almost insignificant in the far field when the Hopkinson-Cranz scaled distance exceeded $5 \mathrm{~m} / \mathrm{kg}^{1 / 3}$ [18]. For IEDs, the charge shape is a critical factor.

Rear detonated cylindrical charges have been shown to generate the highest axial impulses and pressures [19], meaning that they would be expected to produce the highest ball bearing velocities (therefore a worst-case scenario for an IED threat). The influence of the charge aspect ratio on flight characteristics was investigated by Qi et al. [17]. The charge mass was varied but the ball bearing size and mass was kept constant. Aspect ratios below a critical value were more efficient at transferring momentum to the ball bearings. Some preliminary remarks regarding the damage to some of the ball bearings were reported by Qi et al. [20].

This paper reports the results of experimentally informed computational simulations that examine the influence of ball bearing size on the velocity and damage characteristics of an explosively driven single ball bearing. The paper provides detailed insights into the flight characteristics of a ball bearing embedded in a rear detonated cylindrical charge and how its velocity varies with ball bearing mass and diameter, which is of practical relevance to IED research. The location of damage in the ball bearing is also investigated for a range of ball bearing sizes. The paper is arranged as follows. The first section contains a description and summary of validation experiments with explosive charges embedded with a $5 \mathrm{~mm}$ ball bearing. Next, the two simulation approaches are described to determine the flight characteristics and bearing damage, respectively, for different charge and ball bearing sizes. The results of the simulations then follow, showing how the hydrostatic pressure reflections within the bearing were responsible for the cracking experimentally observed. The features of the ball bearing flight are explained with reference to the detonation front and blast pressure propagation observed from the simulations.

These findings will be of practical use to the blast protection engineers considering the flight and damage characteristics of projectiles embedded within IEDs. It will assist in the analysis of specific threats in anti-terrorism, the development of mitigation and disposal devices for IEDs, injury risk predictions, the validation of numerical codes, and post-event forensic analysis.

\section{Validation Experiments with Five Millimetre Diameter Ball Bearing Embedded Charges}

\subsection{Experimental Method}

As the experiments have been reported in prior work by the authors [17], the method is only briefly summarised here. Blast experiments were performed to emulate a simplified IED by half-embedding a $5 \mathrm{~mm}$ diameter SS420-c spherical ball bearing in the front flat surface at the radial centre of a rear-detonated cylindrical charge comprising plastic explosive PE4. The arrangement used in previous research into explosively driven metal [11,12] included metal that either covered the entire face of the charge or encapsulated the entire 
charge. In this work, none of the charge was encased, thus the effects of confinement were removed, allowing the charge geometry influence to be isolated.

The ball bearings were allowed to impact a pair of Al6082-T6 aluminium alloy witness plates (inner and outer) that were placed in front of a Hopkinson pressure bar (HPB). The witness plate assembly was used to capture the cratering characteristics of the ball bearing; the crater depth was used to infer the impact velocity. The outer witness plate was supported by a steel plate and the inner plate was supported by the HPB. This arrangement enabled the tracking of the average and impact velocity of the ball bearing as well as the force history and impulse of the detonation.

\subsection{Ball Bearing Properties}

The sphericity of the ball bearings was measured prior to testing and was found to deviate by less than $1 \mu \mathrm{m}$. The mean mass of the ball bearings was found to be $0.505 \mathrm{~g}$, which was consistent with the $5 \mathrm{~mm}$ diameter and material density of the bearings. Two ball bearings were sectioned, and Vickers hardness tests were conducted on two cross-section samples (using loads of $20 \mathrm{kgf}$ and $30 \mathrm{kgf}$ ). It was determined that the ball bearings had a hardness of 628-648 (HV10), suggesting an ultimate tensile strength range 2098-2173 MPa using DIN 50150 [21]. The yield strength was estimated to be $1685 \pm 100 \mathrm{MPa}$ using Pavlina's correlation [22] for martensitic metals. The ball bearings did not appear to be case hardened as the etched bearing cross-sections showed a consistent microstructure.

\subsection{Flight Characteristics}

A total of 21 experiments were performed, and a computational model for examining the flight behaviour of the ball bearings was developed [17]. The simulations showed good agreement for impact and in-flight velocities when compared to the experiments, as shown in Figure 1 for bearing impact velocity. Thus, the model was validated for its flight behaviour and is extended in this work to examine ball bearing damage and consider other ball bearing sizes.

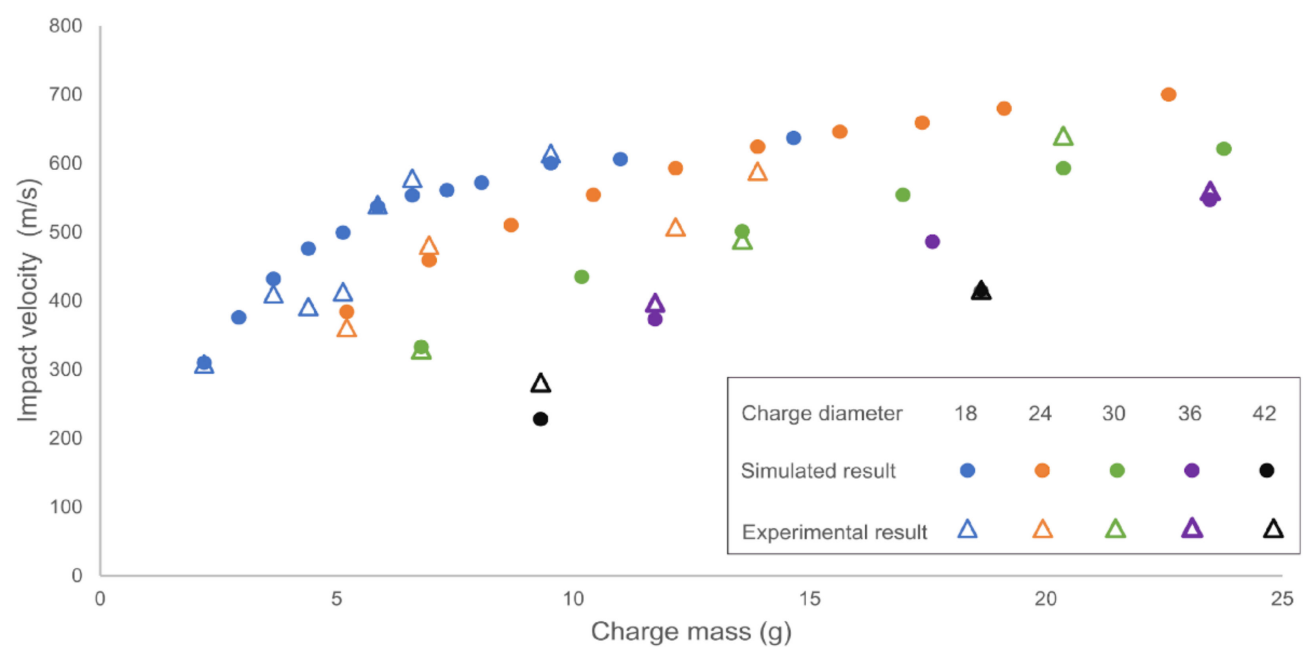

Figure 1. Graph of impact velocity versus charge mass, comparing experiments and simulations using data from.

\subsection{Ball Bearing Damage}

Ball bearings were recovered after the blast tests; however, it was not always possible to identify them immediately after each blast test among the explosive residue. In total, 16 ball bearings were recovered. Two were traced to their experiment. The original work [17] focused on flight characteristics, and ball bearing damage was not reported in detail.

Consistent failure features were observed across the recovered ball bearing, such as the general deformation and the distribution of localised damage. In general, the bearings 
exhibited a shape change, from spherical to ellipsoidal, as demonstrated in Figure 2, with the maximum circumference around the equator demarcating the two hemispheres, one in contact with the explosive (known as Face B) and one not in contact (known as Face A). Prior simulations showed that Face B corresponded to the hemisphere that was embedded within the explosive cylinder (in direct contact), although Face A generally sustained more damage (fragmentation and deformation). The contact hemisphere (Face B) was more spherical than Face A. Face A appeared to have a shinier appearance, while Face B was duller and darker. Fragmentation occurred at the equator but was more concentrated on Face A.
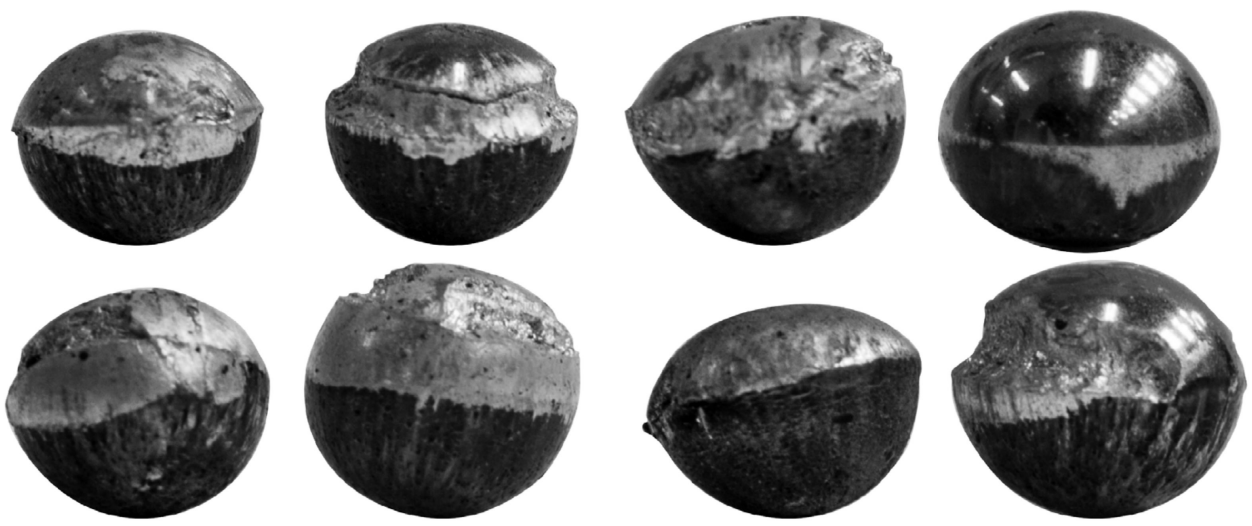

Figure 2. Photographs of typical $5 \mathrm{~mm}$ diameter blast-driven ball bearings showing damage on the two hemispheres after loading under a range of explosive charges and aspect ratios.

The bearings exhibited a "fold" extruded around the equator, with streak marks radiating from the poles of the bearing that were more visible on Face B. The magnified photographs of the ball bearing from the detonation of $5.13 \mathrm{~g}$ of PE4 are shown in Figure 3. In some cases, cracks were observed on Face A, as exemplified in Figure 3a,c. The dullness on Face B was due to the roughened surface (shown in Figure 3b). Internal cracks were also found after cross-sectioning the blasted ball bearings.

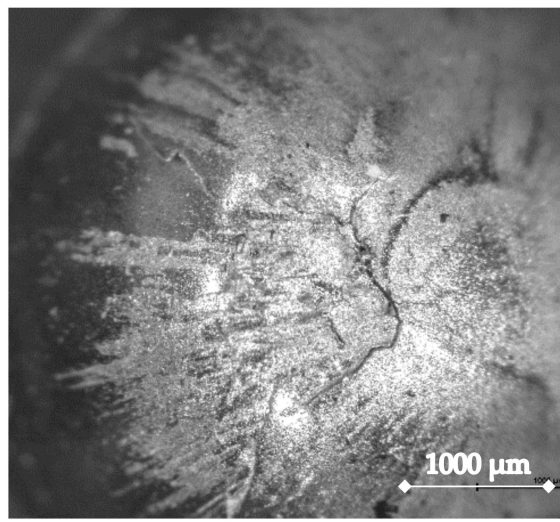

(a)

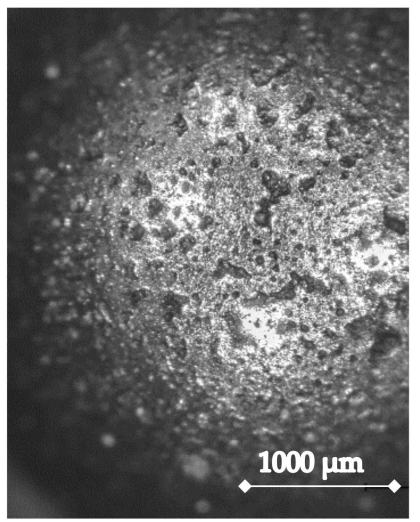

(b)

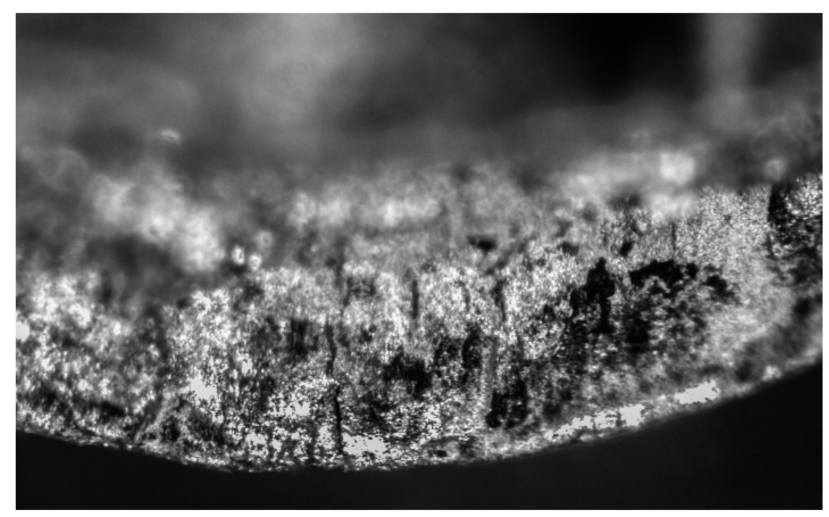

(c)

Figure 3. Photographs of magnified ball bearing damage on (a) Face A, (b) Face B, (c) the cracked region (5.13 $\mathrm{g}$ PE4, $18 \mathrm{~mm}$ charge diameter, $5 \mathrm{~mm}$ diameter ball bearing).

Ball bearings from the gas gun experiments (impact only) and the blast experiments were visually compared. The gas gun experiments, reported in [23], showed no visible damage to the impact-only specimens (due to the nature of the witness plate), meaning that the unique damage features in the blasted bearings were likely to be a result of the blast event alone. 


\section{Simulation Approach}

Two sets of two-dimensional axisymmetric computational simulations were performed using Ansys Autodyn 19.0. The first set, referred to as velocity simulations, followed the approach in reference [17], with the front clamp, back clamp, and HPB modelled as fixed boundaries. The witness plates were modelled using two rectangular parts and their rear faces were fixed in the x-direction. A $3.2 \mathrm{~mm}$ line detonation was used to simulate the $6.4 \mathrm{~mm}$ detonator used in the validation blast tests. The detonation simultaneously initiated across its line in the simulation. A schematic, shown in Figure 4a, defines the positioning of the parts, the dimensions of the model, and the boundary conditions for the velocity simulation approach. The bearing diameter was varied in the $3-10 \mathrm{~mm}$ range.

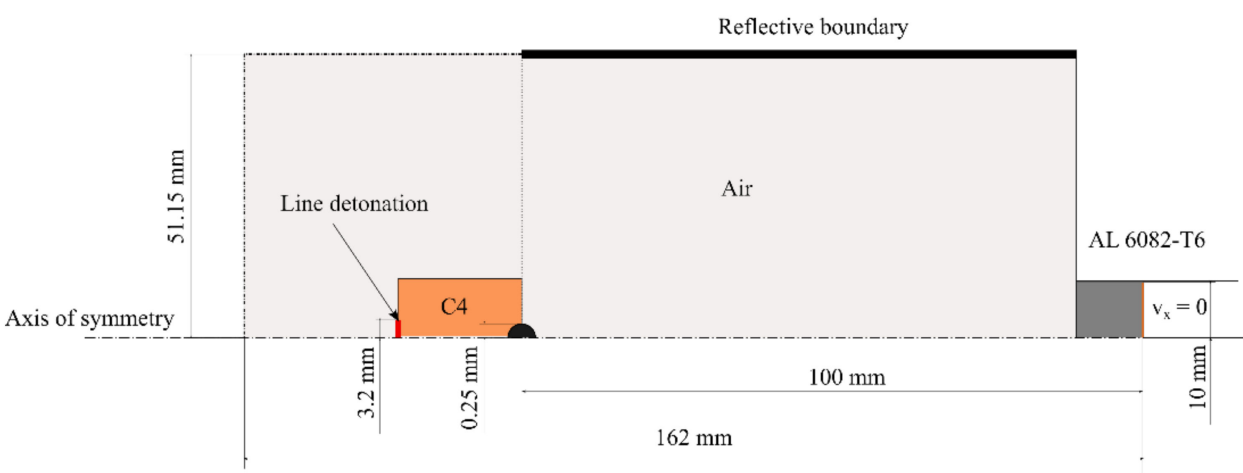

Legend

\begin{tabular}{l|l|l|l|l|l} 
Matcrials & Air & AL 6082-T6 & Stainless Steel & C4
\end{tabular}

(a)

Outflow boundary

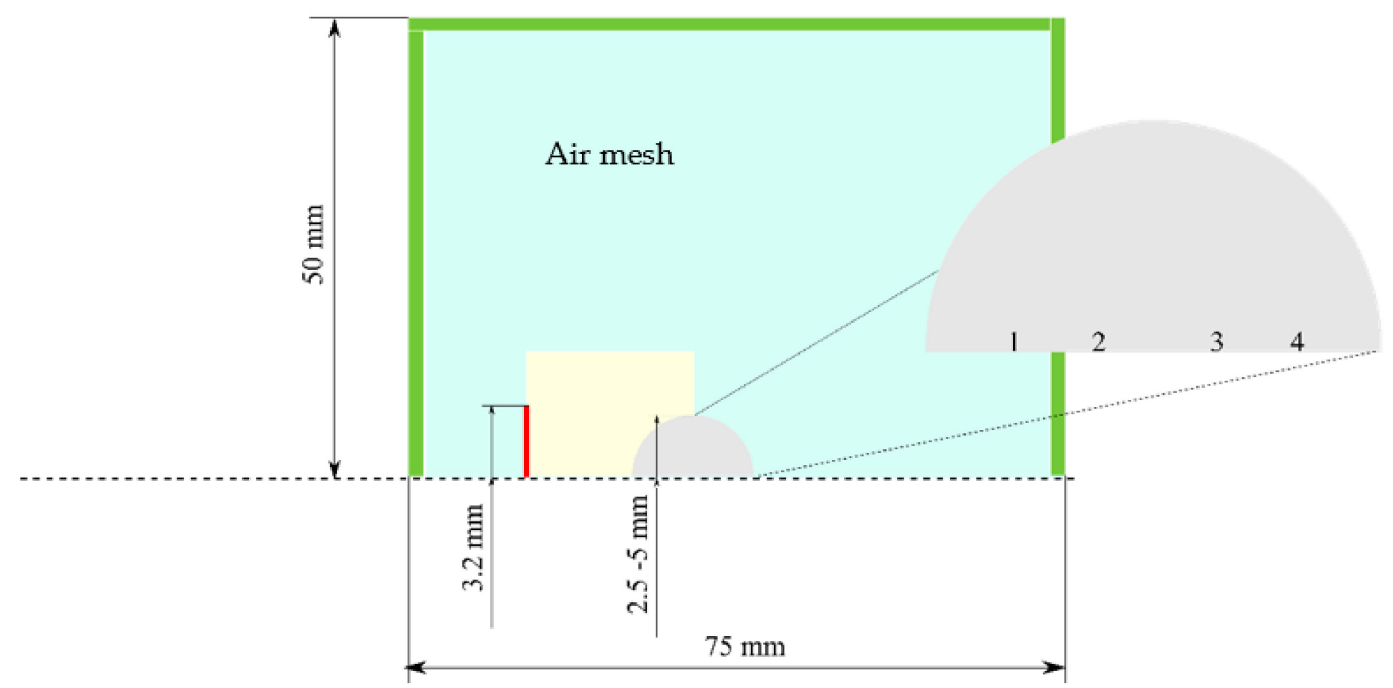

(b)

Figure 4. Schematic showing the geometry and boundary conditions used in (a) the velocity simulations and (b) the ball bearing simulations with an inset to represent the approximate locations of the four gauges used in the hydrostatic pressure histories.

The second set of simulations, referred to as ball bearing simulations, included a much finer bearing mesh size and a damage model for the bearing material. A principal stress failure model was used to capture the internal spalling mechanism; a schematic of this approach is shown in Figure $4 \mathrm{~b}$. It employed a $75 \mathrm{~mm}$ by $50 \mathrm{~mm}$ air mesh with a ball bearing modelled with a very fine mesh of $0.02 \mathrm{~mm}$ across the ball diameter. The very 
fine mesh meant that the ball bearing simulations were very computationally expensive, therefore they were run for a very short time to capture the failure of the bearings and did not include the modelling of the clamps, aluminium plates, or the tube sides (which only became important in later stages of the flight).

In both sets of simulations, a $0.2 \mathrm{~mm}$ mesh side length was chosen for the air and explosive parts. This allowed for a minimum of 45 elements (18 mm diameter charge) across the charge radius.

\subsection{Air, PE4, and Witness Plate Modelling}

The air was modelled using the ideal gas equation of state and PE4 was modelled using the Jones-Wilkins-Lee EOS shown in Equation (1):

$$
P=A\left(1-\left(\frac{\omega}{R_{1} V}\right)\right) e^{-R_{1} V}+B\left(1-\left(\frac{\omega}{2 V}\right)\right) e^{-R_{2} V}+\left(\frac{\omega E}{V}\right)
$$

where $P=$ pressure, $V=$ specific volume, $E=$ energy, and $\omega, A, B, R_{1}, R_{2}=$ JWL parameters (explosive specific constants).

The properties used are shown in Table 1 . Similar to others $[17,24,25]$, the JWL parameters for C4 were used to model PE4 [26] as they contained similar proportions of the active explosive RDX. Details of the air and PE4/C4 model parameters are in Table 1 (where $\gamma=$ ratio of specific heat capacities). The aluminium alloy witness plates were modelled using the Johnson-Cook model [27] and the properties are shown in Table 2, based on Yibo et al. [28] and test results from the previous experiments [17].

Table 1. Properties of air and C4 used in the simulations.

\begin{tabular}{ccccccccccc}
\hline & $\begin{array}{c}\text { Density } \\
\left(\mathbf{k g} / \mathbf{m}^{3}\right)\end{array}$ & $\gamma$ & $\begin{array}{c}\text { Specific } \\
\text { Heat } \\
(\mathbf{K} / \mathbf{k g K})\end{array}$ & A (GPa) & B (GPa) & $\mathbf{R}_{\mathbf{1}}$ & $\mathbf{R}_{\mathbf{2}}$ & $\mathbf{W}$ & $\begin{array}{c}\text { CJ } \\
\text { Velocity } \\
(\mathbf{m} / \mathbf{s})\end{array}$ & $\begin{array}{c}\text { CJ } \\
\text { Pressure } \\
\mathbf{( G P a )}\end{array}$ \\
\hline $\begin{array}{c}\text { Air (ideal gas law) } \\
\text { C4 (JWL EOS) }\end{array}$ & 1.225 & 1.4 & 717.6 & 610 & 13 & 4.5 & 1.4 & 0.25 & 8190 & 28 \\
\hline
\end{tabular}

Table 2. Properties of aluminium alloy AA6082-T6 used in the simulations.

\begin{tabular}{cccccc}
\hline $\begin{array}{c}\text { Shear Modulus } \\
(\mathrm{GPa})\end{array}$ & $\begin{array}{c}\text { Yield Strength } \\
(\mathbf{M P a})\end{array}$ & $\begin{array}{c}\text { Hardening } \\
\text { Constant (MPa) }\end{array}$ & $\begin{array}{c}\text { Hardening } \\
\text { Exponent }\end{array}$ & $\begin{array}{c}\text { Strain Rate } \\
\text { Constant }\end{array}$ & $\begin{array}{c}\text { Thermal Softening } \\
\text { Exponent }\end{array}$ \\
\hline 27.6 & 306 & 304.9 & 0.68 & $4.37 \times 10^{-3}$ & 1 \\
\hline
\end{tabular}

\subsection{Modelling the Ball Bearing Deformation}

This new model improved on prior work [17] by including failure criteria to examine the damage evolution in the ball bearing. The Johnson-Cook strength parameters and maximum principal stress failure criteria used for the SS420 [29] are presented in Table 3. Numerical pressure gauges were placed at $0.4 \mathrm{~mm}$ intervals across the rear face of the blast tube and gauges were placed at regular intervals inside the ball bearing to examine the stress fluctuations at four approximate locations within the bearing during the blast event and subsequent flight (indicated in Figure $4 b$ ). Similar configurations were used for each bearing size. The ball bearing diameter range was from $3 \mathrm{~mm}$ to $10 \mathrm{~mm}$ and varied according to the requirement. 
Table 3. Properties of the ball bearing material used in simulations.

\begin{tabular}{ccccccc}
\hline & \multicolumn{3}{c}{ Johnson-Cook Strength Model } & & \multicolumn{2}{c}{ Principal Stress Damage Model } \\
\hline $\begin{array}{c}\text { Shear Modulus } \\
(\text { GPa) }\end{array}$ & $\begin{array}{c}\text { Yield Stress } \\
\mathbf{( M P a )}\end{array}$ & $\begin{array}{c}\text { Hardening Constant } \\
\mathbf{( M P a )}\end{array}$ & $\begin{array}{c}\text { Hardening } \\
\text { Exponent }\end{array}$ & $\begin{array}{c}\text { Strain Rate } \\
\text { Constant }\end{array}$ & $\begin{array}{c}\text { Tensile Failure } \\
\text { Stress }\end{array}$ & $\begin{array}{c}\text { Shear Failure } \\
\text { Stress }\end{array}$ \\
80 & 2173 & 1785 & 0.6 & $0.023[29]$ & 21 & $(\mathbf{M P a})$ \\
\hline
\end{tabular}

\section{Simulation Results and Discussion}

A summary of the flight characteristics predicted using the velocity simulations is provided in Table 4. Figure 5 shows the predicted velocity-time histories for the first $10 \mu \mathrm{s}$ from the velocity simulation approach and the ball bearing simulation approach. The results are separated by charge diameter for ease of interpretation. The different times after detonation at which the velocity sharply increased are due to the height of the explosive charge. Increased charge heights mean the detonation wave must travel further to reach the ball bearing, delaying the transfer of momentum to the bearing as expected.

Table 4. Summary of flight characteristics obtained from the velocity simulations using different diameter ball bearings and charge masses.

\begin{tabular}{|c|c|c|c|c|c|c|c|}
\hline $\begin{array}{c}\text { Charge Mass } \\
\text { (g) }\end{array}$ & $\begin{array}{c}\text { Charge } \\
\text { Diameter }(\mathrm{mm})\end{array}$ & $\begin{array}{c}\text { Aspect } \\
\text { Ratio }\end{array}$ & $\begin{array}{c}\text { Ball Bearing } \\
\text { Diameter }(\mathrm{mm})\end{array}$ & $\begin{array}{l}\text { Ball Bearing } \\
\text { Mass (g) }\end{array}$ & $\begin{array}{l}\text { Impact } \\
\text { Velocity }\end{array}$ & $\begin{array}{l}\text { Mean Plateau } \\
\text { Velocity }\end{array}$ & $\begin{array}{c}\text { Peak } \\
\text { Velocity }\end{array}$ \\
\hline 5.13 & 18 & 0.7 & 3 & 0.11 & 711 & 720 & 795 \\
\hline 5.13 & 18 & 0.7 & 5 & 0.51 & 498 & 505 & 540 \\
\hline 11.0 & 18 & 1.5 & 5 & 0.51 & 616 & 622 & 664 \\
\hline 11.0 & 18 & 1.5 & 8 & 2.09 & 426 & 428 & 452 \\
\hline 20.37 & 30 & 0.6 & 5 & 0.51 & 572 & 573 & 701 \\
\hline 27.16 & 30 & 0.8 & 5 & 0.51 & 623 & 625 & 781 \\
\hline 20.37 & 30 & 0.6 & 8 & 2.09 & 448 & 449 & 507 \\
\hline 27.16 & 30 & 0.8 & 8 & 2.09 & 497 & 498 & 570 \\
\hline 20.37 & 30 & 0.6 & 10 & 4.08 & 384 & 385 & 426 \\
\hline 27.16 & 30 & 0.8 & 10 & 4.08 & 436 & 437 & 482 \\
\hline
\end{tabular}

Figure 5a shows that, for the $18 \mathrm{~mm}$ charge diameter, there was a negligible (less than $1 \%$ ) difference in the velocity histories in each case, except in the $3 \mathrm{~mm}$ ball bearing simulation where the peak velocity was approximately $3 \%$ higher in the velocity approach. For the $30 \mathrm{~mm}$ diameter charges, shown in Figure $5 \mathrm{~b}$, the velocity simulation approach provided similar predictions to the ball bearing approach but with slightly $(1-3 \%)$ lower peak velocities.

The results show that including damage modelling in the ball bearing has a negligible effect on its flight characteristics. This means the velocity simulations can be used with reasonable confidence based on the good agreement here and the satisfactory correlation with experiments demonstrated in reference [17]. Throughout the following sections of the paper, the velocity simulation results are used when describing the bearing flight characteristics, while the bearing simulation approach is used to elucidate the failure and damage within the ball bearings. 


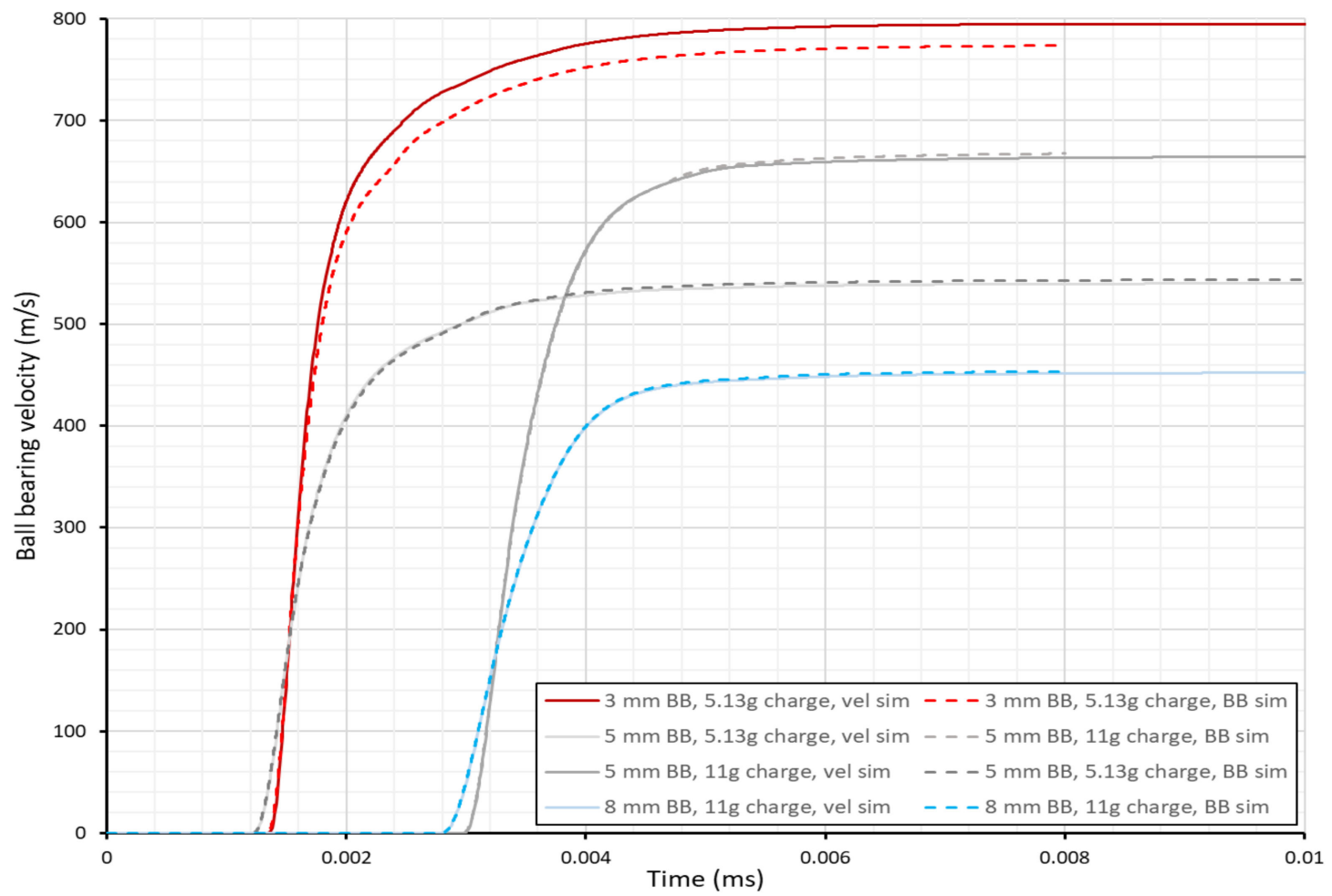

(a)

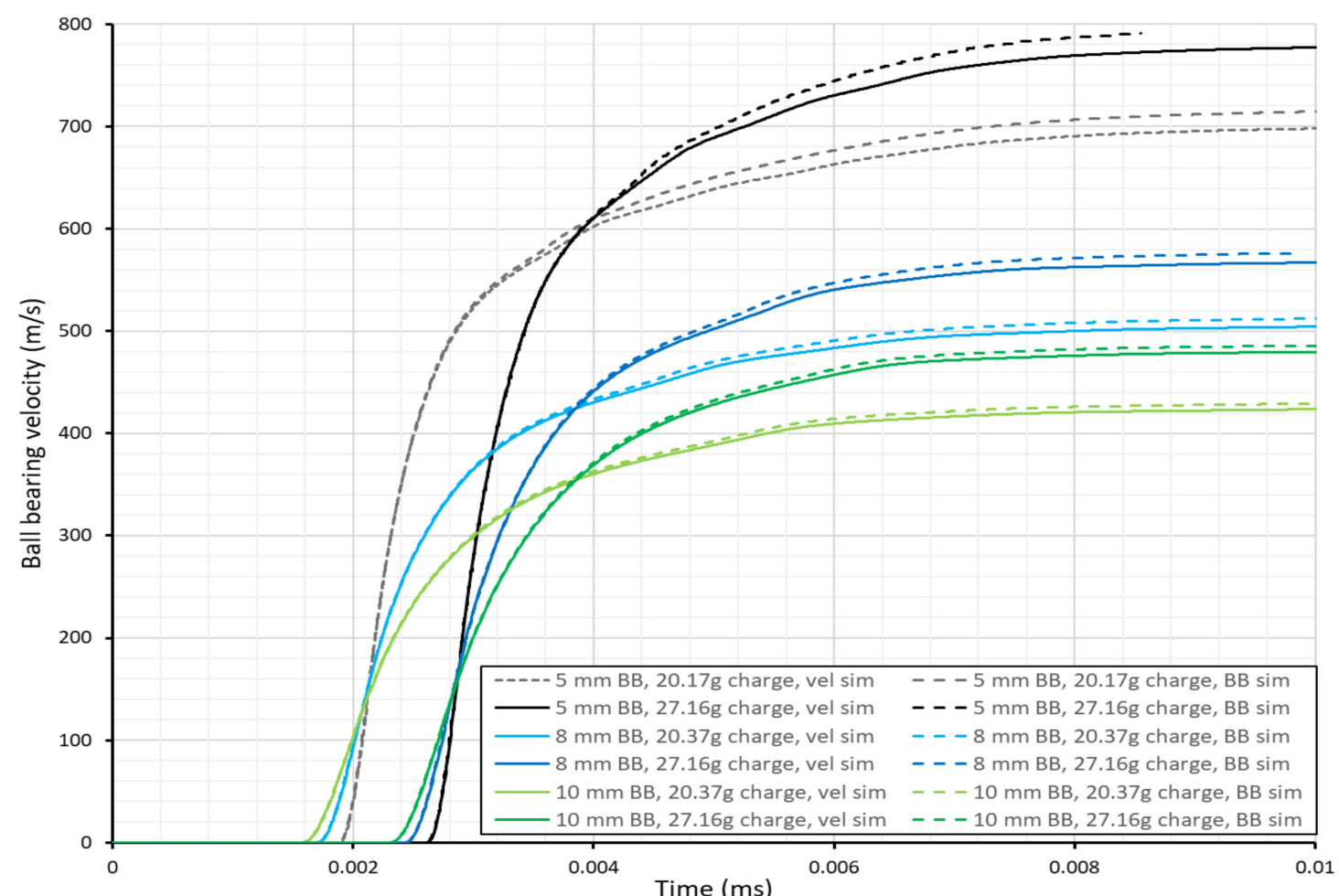

(b)

Figure 5. Ball bearing velocity-time histories for the first $10 \mu \mathrm{s}$, comparing the velocity simulation approach and the ball bearing simulation approach. (a) $18 \mathrm{~mm}$ diameter charge detonations, (b) $30 \mathrm{~mm}$ diameter charge detonations. 


\subsection{Three Millimetre and Five Millimetre Diameter Ball Bearings}

Figure 6 shows the simulated velocity histories for $3 \mathrm{~mm}$ and $5 \mathrm{~mm}$ diameter bearings subjected to different charge mass detonations. The phases of flight are similar to those in [17]. There was a rapid rise in velocity followed by a constant peak velocity once the blast momentum was transferred to the bearing. As expected, the peak velocity increased with an increasing charge mass and was greater for the lighter $3 \mathrm{~mm}$ diameter ball bearing.

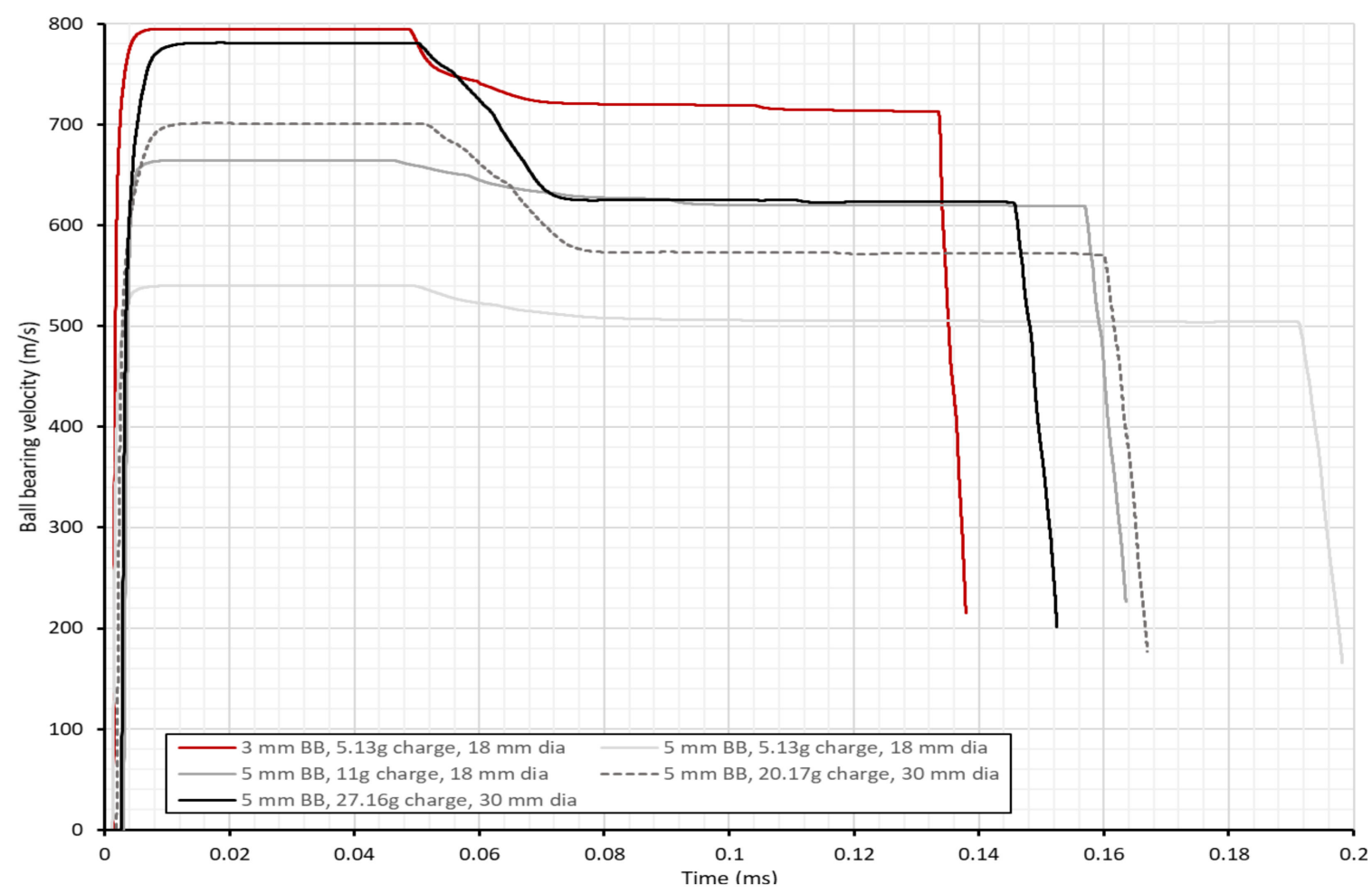

Figure 6. Simulated velocity-time histories for $3 \mathrm{~mm}$ and $5 \mathrm{~mm}$ diameter ball bearings at different charge masses, from detonation to impact point.

A slight drop in velocity is predicted when the blast wave reflection from the witness plate opposes the bearing motion. The percentage velocity drop ranged from approximately $4 \%$ to $20 \%$, with larger percentage decreases observed for higher charge masses and charge diameters (as the reflected shock pressure will be greater). A plateau phase ensued prior to impact with the witness plate; the impact caused a rapid linear deceleration of the bearing until it stopped.

The results from a $5.13 \mathrm{~g}$ detonation ( $18 \mathrm{~mm}$ diameter charge) are shown in Figures 7 and 8 as this was one of the few experiments in which the ball bearing was recovered and identified. Face $B$ was the side of the bearing embedded in the explosive charge. The hydrostatic pressure history for gauges in hemispheres A and B are shown in Figure 7a. In general, gauges 4 and 10 (Face B) had similar pressure histories but different arrival times, as expected. The initial compressive stress wave propagated from gauges 4 and 10 with similar magnitude (approximately $32 \mathrm{GPa}$ ) and, in Figure 7c, the shape of the compressive stress front is curved as it passes gauge 10 (after $1.4 \mu \mathrm{s}$ ). 


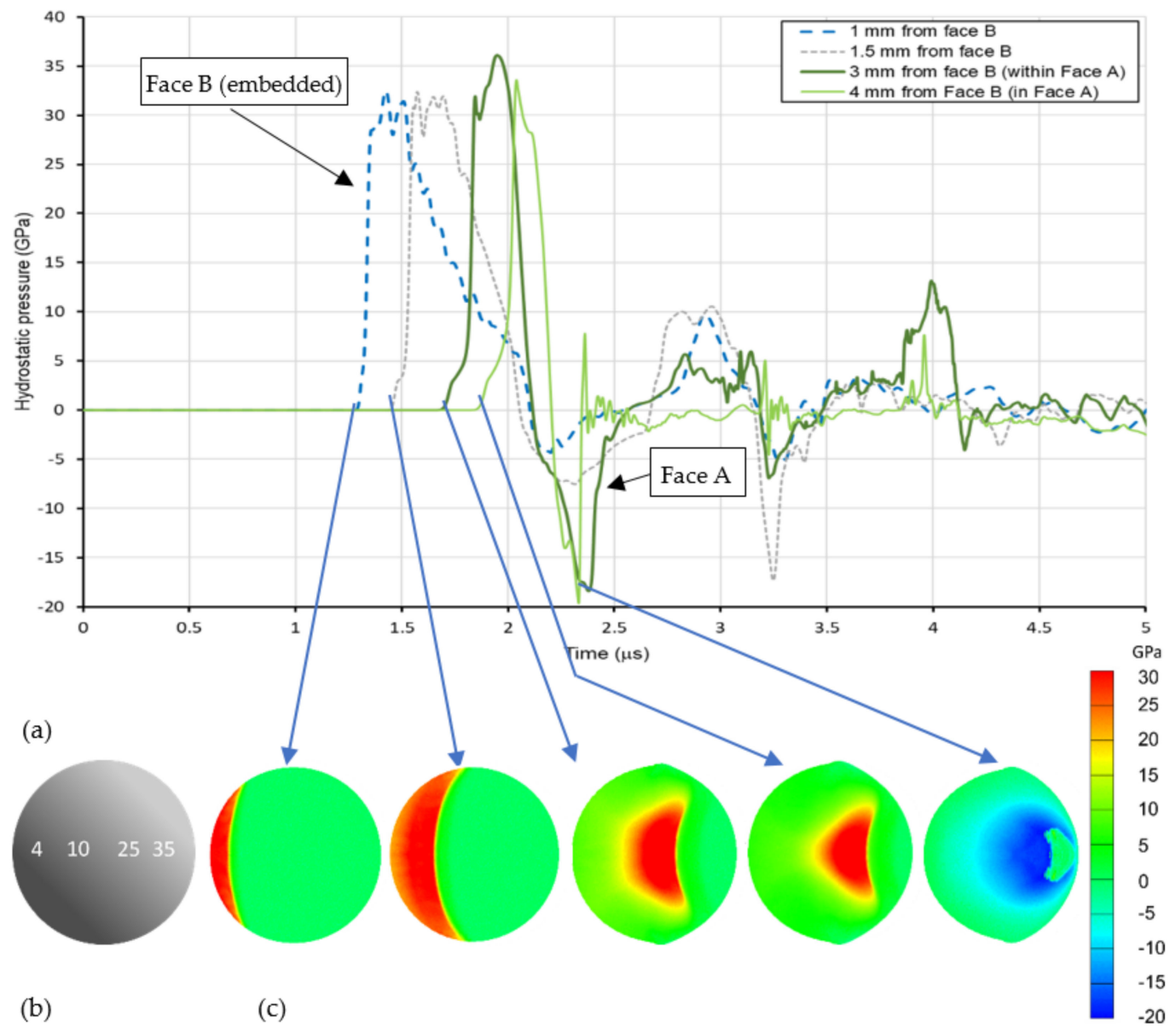

Figure 7. Simulated hydrostatic pressure development in a $5 \mathrm{~mm}$ ball bearing subjected to a $5.13 \mathrm{~g}$ charge. (a) Hydrostatic pressure history, where positive pressure indicates compression, (b) gauge locations on the ball bearing, (c) hydrostatic pressure contour plots at times after detonation that correspond to significant points in the hydrostatic pressure-time history (as indicated).
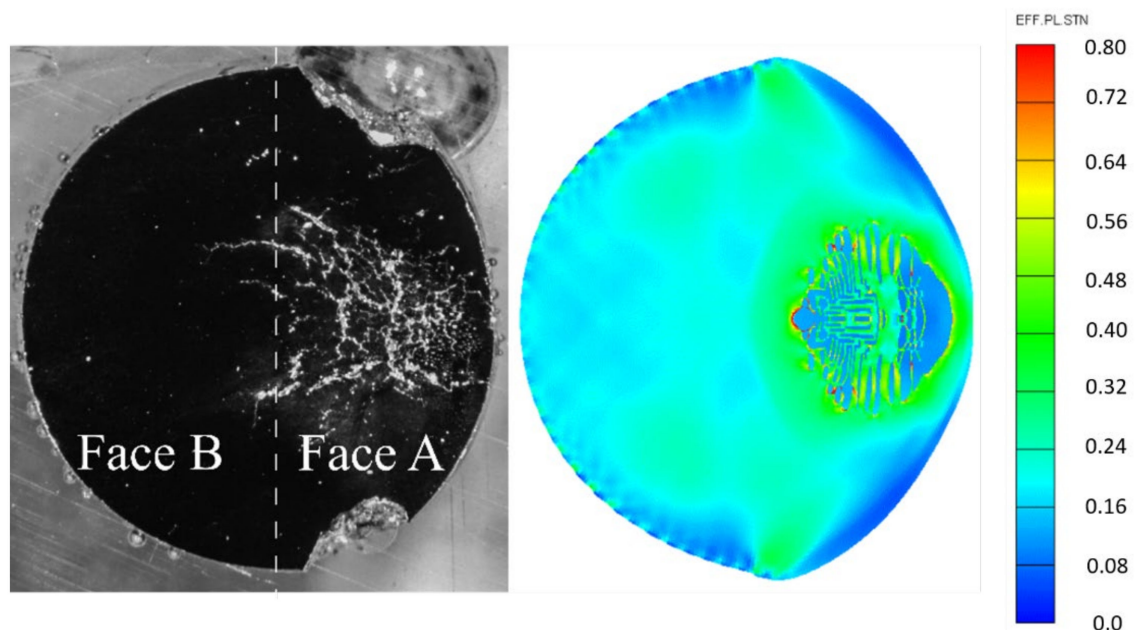

Figure 8. Photograph of the sectioned ball bearing from a $5.13 \mathrm{~g}$ detonation (left) and the simulated effective plastic strain contour $2.5 \mu$ s after detonation (right).

The peak pressure increased to approximately 36 GPa on Face A at gauge 25 (after approximately $1.7 \mu \mathrm{s}$, Figure 7) as there was a focusing effect due to the curvature. This strengthened compressive wave was reflected as a tensile wave (indicated by the negative 
hydrostatic pressure in Figure 8 at $2.2 \mu \mathrm{s}$ ) and reached a maximum at $2.3 \mu \mathrm{s}$, which caused internal cracking as the tensile stress exceeded the maximum tensile failure stress of $21 \mathrm{GPa}$. At $2.3 \mu \mathrm{s}$, the material at gauge 35 had failed, indicated by the negative pressure spike and its sudden relaxation to near-zero pressure. It is worth noting that the ball bearing had not yet reached its peak velocity by this point (Figure 5a).

Figure 8 shows an image of the simulated equivalent plastic strain distribution in the ball bearing and a photograph of the cross-section of the blasted bearing. Internal cracking was observed in the cross-section of the bearing in the same location as the simulated internal cracks. Lastly, while the model did not indicate fragmentation around the equator, the maximum effective plastic strain was shown to be in a similar region as the actual fragmented location. The hydrostatic pressure history also showed a peak in the tensile stress at gauge 10 (Face B) after $3.2 \mu$ s, but the magnitude was slightly less than the tensile failure stress, hence there was no cracking in that region of the previously embedded hemisphere. The lack of fragmentation in the model could be due to the limited capability of the failure model used in the simulation.

The simulations showed that internal cracks (Figures 7 and 8 ) formed due to tensile spalling. The location of the cracking was a result of the geometry of the ball bearing as the hydrostatic pressure waves reflected from the curved free surface of Face A and caused an internal hydrostatic tensile pressure state that coincided at the crack location. The simulations also predicted the evolution of the deformed shape, with Face B remaining spherical and Face A flattening over a very short time (within $2.5 \mu$ s of detonation).

\subsection{Eight Millimetre and Ten Millimetre Diameter Ball Bearings}

As might be expected, the heavier ball bearings required larger charge masses to accelerate them to similar peak velocities, as shown in Figure 9. The phases of flight were similar to those observed in simulations of other ball bearing sizes and in the $5 \mathrm{~mm}$ diameter ball bearing experiments reported in [17]. Peak velocity increased with an increasing charge mass for a given charge diameter but was less sensitive to charge mass when the charge diameter was increased to $30 \mathrm{~mm}$. The drop in velocity due to interaction with the reflected blast waves from the witness plates increased with increasing charge mass.

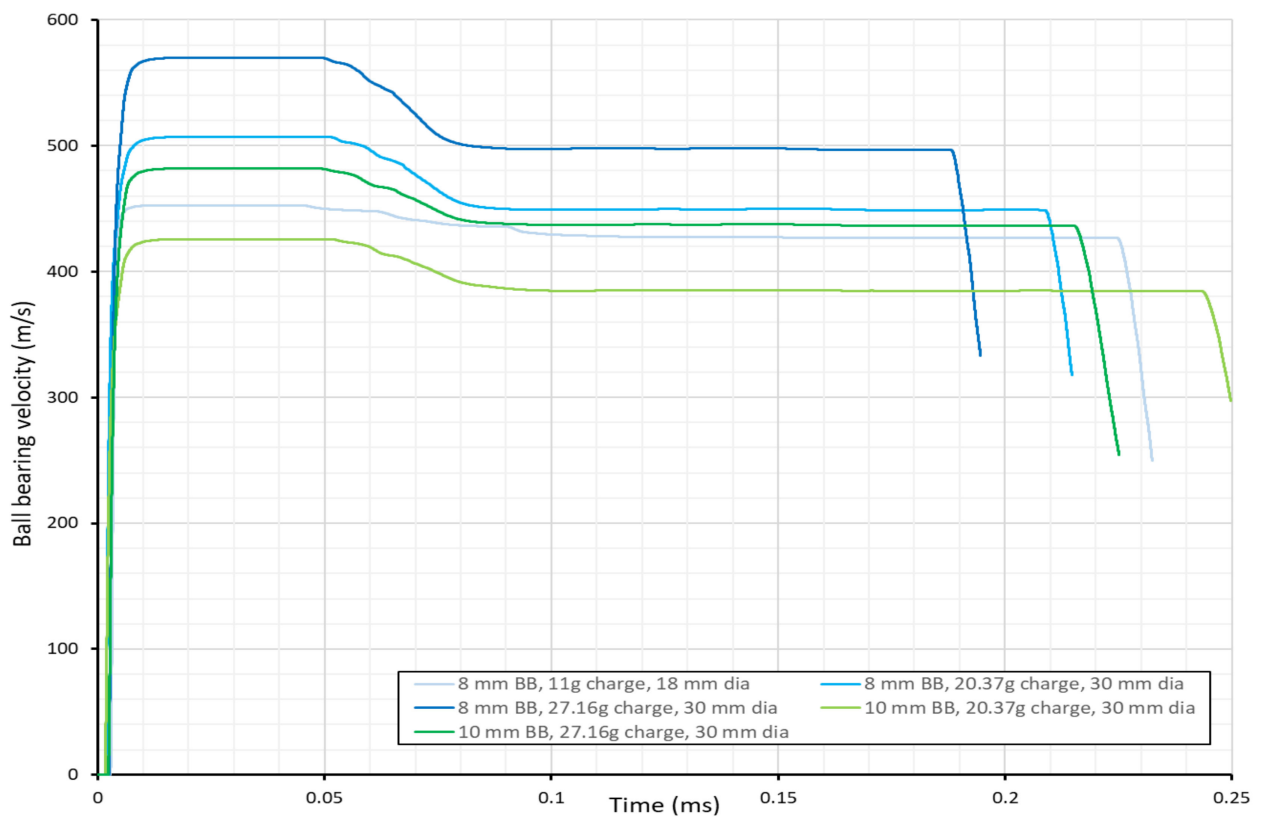

Figure 9. Simulated ball bearing velocity-time histories for $8 \mathrm{~mm}$ and $10 \mathrm{~mm}$ diameter ball bearings at different charge masses.

The simulated hydrostatic pressure histories for $8 \mathrm{~mm}$ ball bearings from two different explosive charge detonations are shown in Figure 10. The shapes of the two sets of 
pressure progressions are similar. A high pressure (slightly over $30 \mathrm{GPa}$ ) compressive stress propagated through the bearing and then reflected back as a tensile wave from the free surface of Face A. Similar hydrostatic pressure histories were obtained for the $10 \mathrm{~mm}$ diameter ball bearings (not shown).

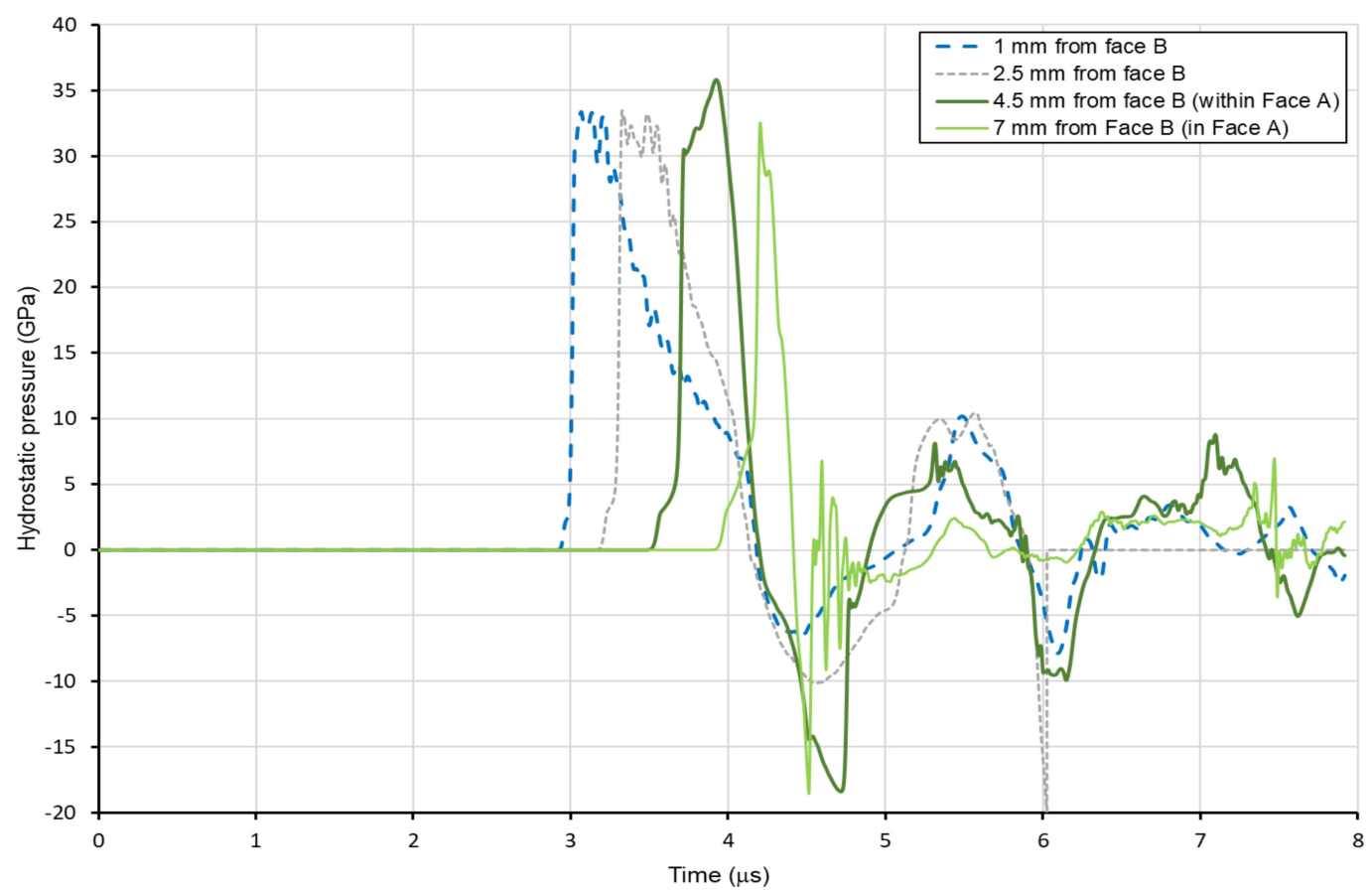

(a)

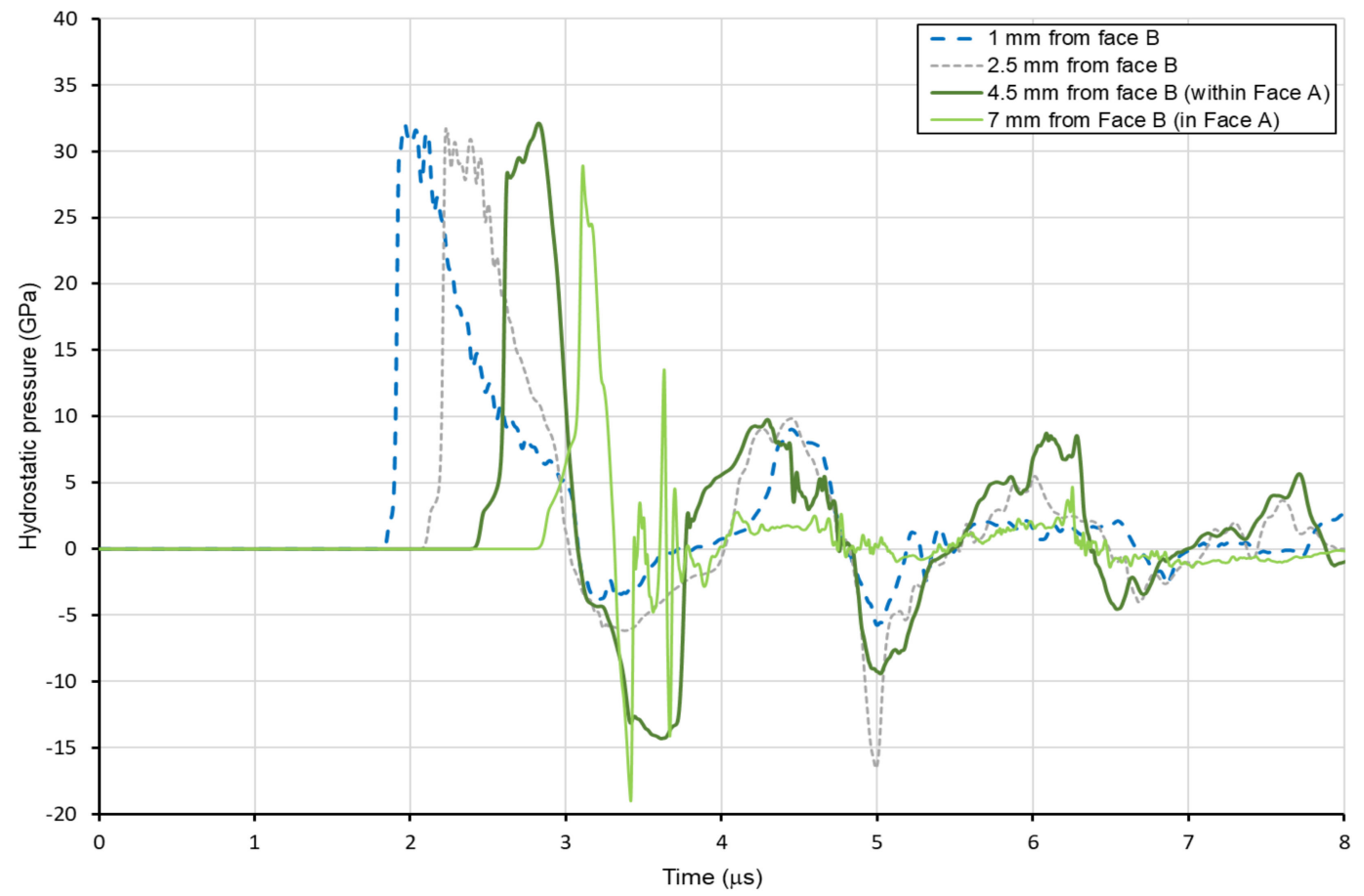

(b)

Figure 10. Simulated hydrostatic pressure development in an $8 \mathrm{~mm}$ ball bearing subjected to (a) $11 \mathrm{~g}$ charge, $18 \mathrm{~mm}$ diameter, (b) $20.37 \mathrm{~g}$ charge, $30 \mathrm{~mm}$ diameter.

The arrival time for the hydrostatic compressive stress in Face B (the embedded side) was earlier in the higher charge mass simulation, as shown in Figure 10. This was due 
to the higher charge diameter and hence the shorter charge length of the $20.37 \mathrm{~g}$ charge, meaning that the detonation wave travelled further to reach the bearing in the $11 \mathrm{~g}$ charge. Interestingly, the $11 \mathrm{~g}$ charge detonation resulted in higher compressive and tensile peak stresses within the bearing, despite a lower predicted peak velocity (Figure 9).

The tensile stresses observed near the free surface of Face A appeared "noisy" (after 3-4 $\mu$ s in Figure 10a, 4-5 $\mu$ s in Figure 10b). The discontinuities are attributed to extensive cracking in the bearing. There was a second tensile peak in Face B approximately $6 \mu \mathrm{s}$ after detonation in Figure 10a, with a magnitude of approximately 20 GPa. With a similar but lower magnitude (approximately $16 \mathrm{GPa}$ ), a secondary tensile peak in Face B was observed in the $20.37 \mathrm{~g}$ detonation simulation (Figure 10b) after approximately $5 \mu \mathrm{s}$. This may indicate that the tensile failure in both halves of the ball bearing would occur in the $11 \mathrm{~g}$ detonation but not in the $20.37 \mathrm{~g}$ case. This suggests that the aspect ratio of the charge significantly influences both the bearing flight characteristics and the damage predicted within the ball bearing, with higher aspect ratio charges inflicting greater damage than lower aspect ratio ones.

One of the limitations of the current modelling is the lack of a fracture and fragmentation model for the ball bearing, limited by the available computational approaches to this highly complex and non-linear problem and the lack of well-defined parameters for the bearing materials itself. Nonetheless, the current simulations show that it is certainly possible at higher charge masses (and appropriate aspect ratios) for detonations to generate internal hydrostatic stresses within the ball bearing that are capable of breaking the bearing into multiple fragments within the first few microseconds of the load applications. The short time to fracture will influence the flight characteristics of the subsequent fragments both in terms of trajectory and velocity magnitude. This has implications for IED research, where embedded solid objects within the charge contribute to many IED-related injuries and deaths.

\subsection{Insights into the Influence of Ball Bearing Size}

Figure 11 shows the velocity histories for $27.16 \mathrm{~g}$ charge mass, $30 \mathrm{~mm}$ charge diameter (aspect ratio of 0.8) detonations with different sized ball bearings. As might be expected, the peak velocities of the heavier ball bearings were lower ( $27 \%$ drop for the $8 \mathrm{~mm}$ bearing, $38 \%$ drop for the $10 \mathrm{~mm}$ bearing, both compared to the peak of the $5 \mathrm{~mm}$ ball bearing). Considering that the ball bearing mass increased fourfold for the $8 \mathrm{~mm}$ bearing and eightfold for the $10 \mathrm{~mm}$ bearing, these velocities decreases are smaller than might be expected. Figure 12 shows a graph of peak ball bearing velocity versus the ratio of charge mass to ball bearing mass; here, it is evident from the current work and our previous simulation results [17] that there are other factors of importance other than mass ratio, such as charge shape.

It is also notable in Figure 11 that the biggest decrease in the peak velocity caused by the reflected pressure interactions occurred for the $5 \mathrm{~mm}$ ball bearing $(20 \%)$, with only a $9 \%$ drop for the heaviest $10 \mathrm{~mm}$ bearing. The decrease in velocity due to the bearing interaction with the reflected blast pressure from the witness plate is influenced by the charge mass/ball bearing mass ratio and the aspect ratio of the charge. This is shown in Figure 13, where it is evident that the $30 \mathrm{~mm}$ diameter charges exhibited greater sensitivity to charge mass increases than the $18 \mathrm{~mm}$ diameter charge detonations. The percentage decreases were greater for the $30 \mathrm{~mm}$ charges, ranging from $10 \%$ to $20 \%$, compared with $5 \%$ to $10 \%$ for the $18 \mathrm{~mm}$ charges. 


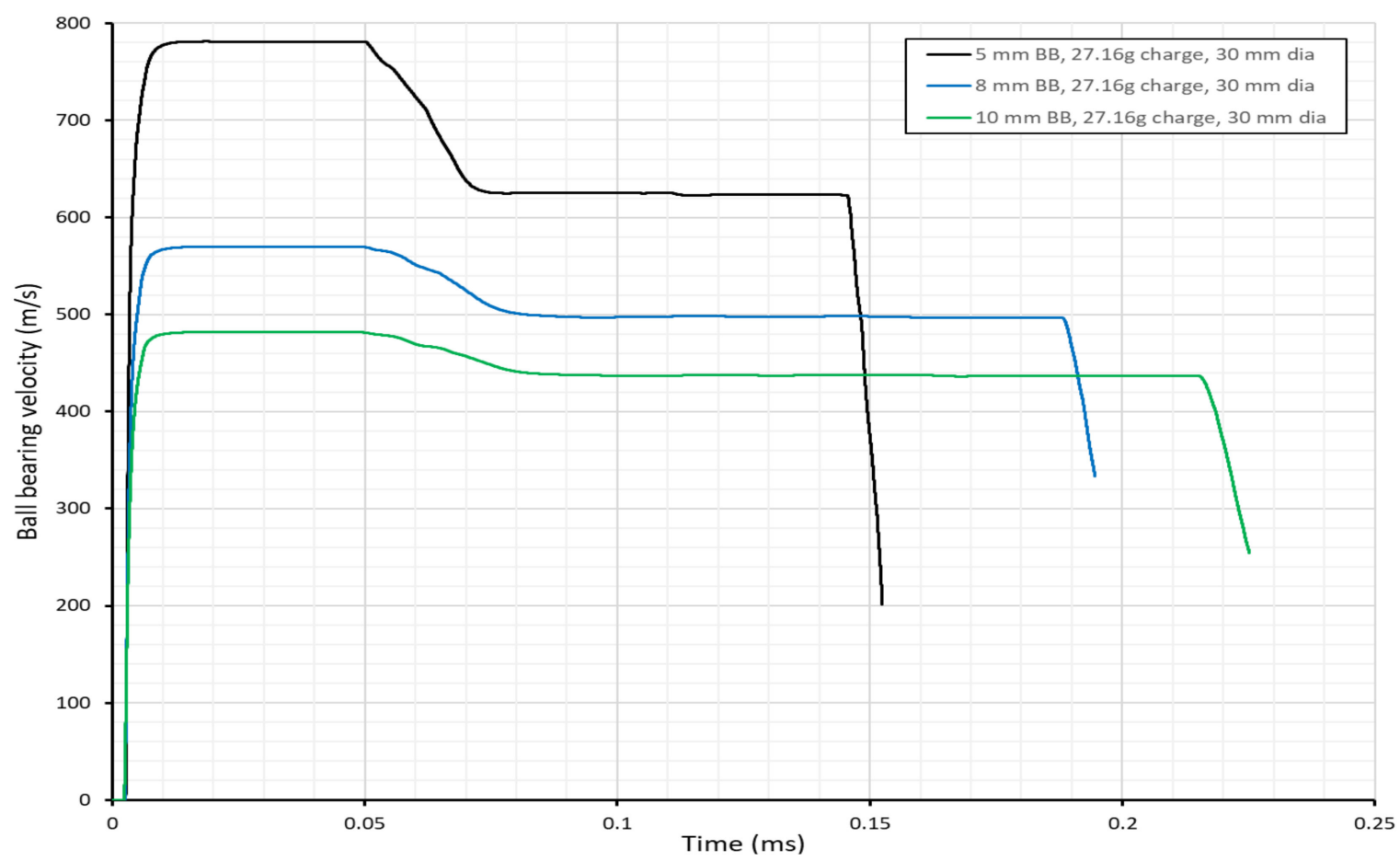

Figure 11. Simulated velocity-time histories for $27.16 \mathrm{~g}$ charge mass (30 $\mathrm{mm}$ charge diameter) detonations with different sized ball bearings.

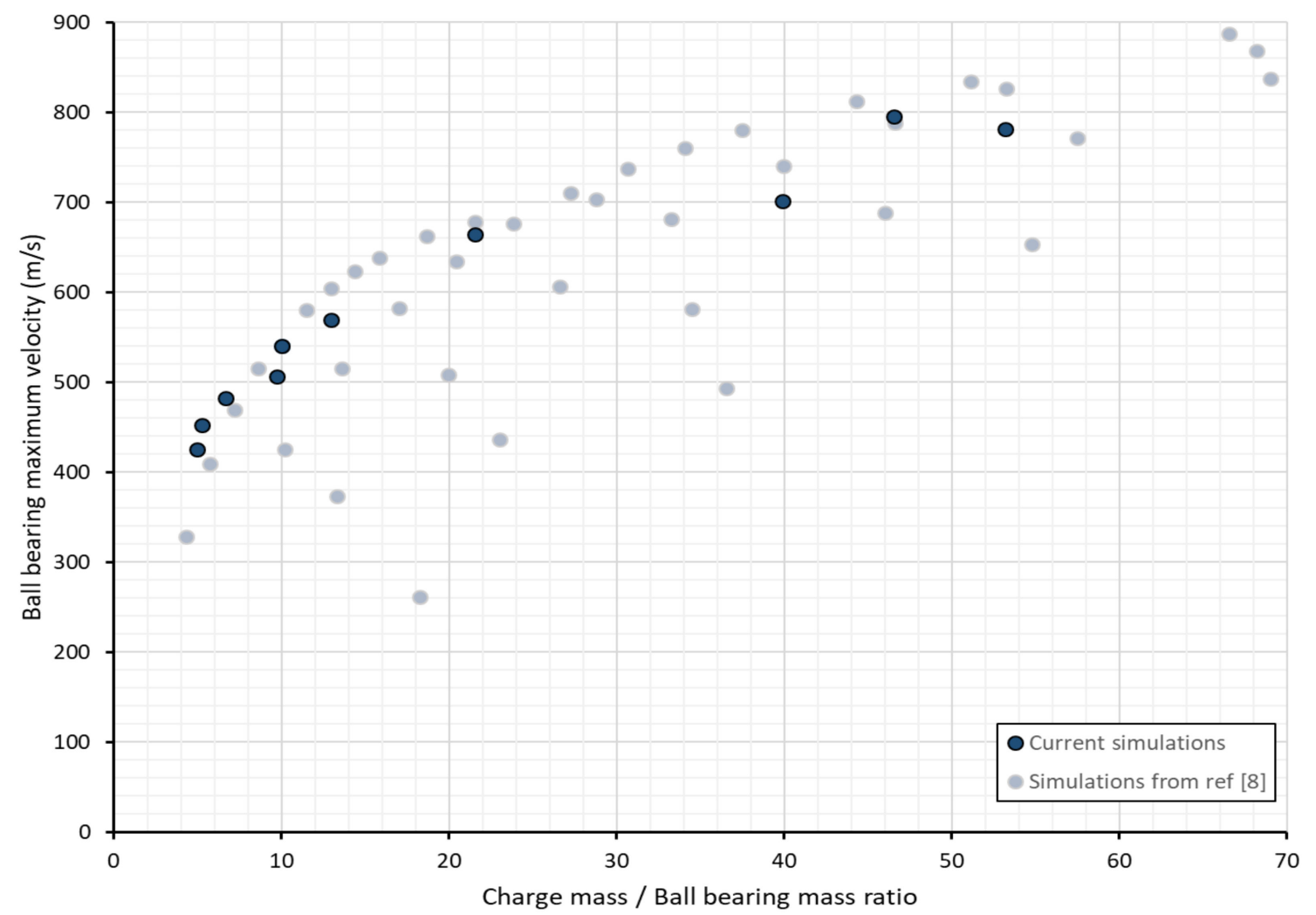

Figure 12. Graph of maximum ball bearing velocity versus charge mass/ball bearing mass ratio. 


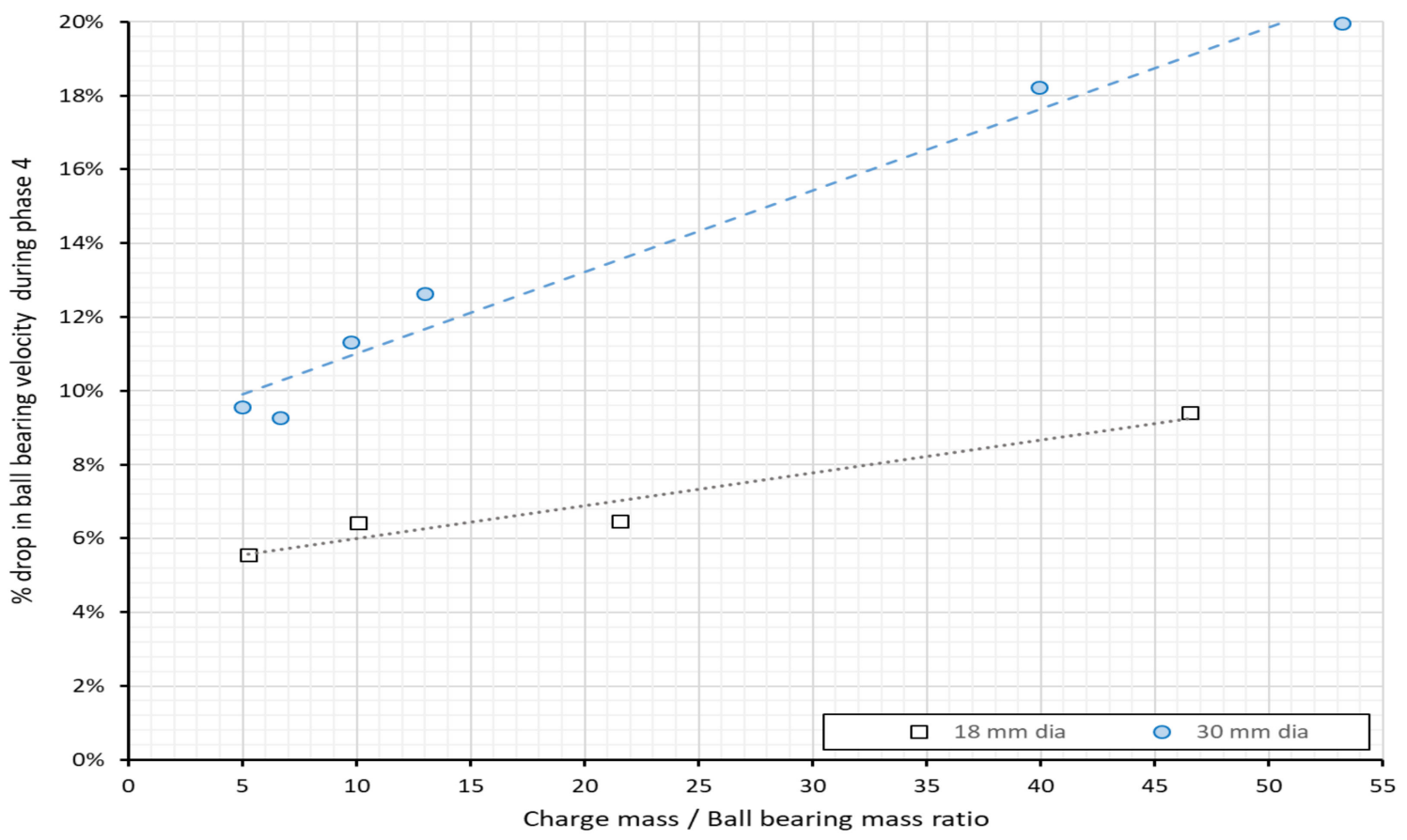

Figure 13. Graph of percentage decrease in ball bearing velocity during phase 4 versus charge mass/ball bearing mass ratio.

These observations concerning peak velocity and the sharp drop in velocity can be explained by considering the pressure distribution following detonation, its interaction with the ball bearing, and the implications for the later reflected pressure interactions. Our previous work [8] showed that explosive charges with aspect ratios below a critical value were more efficient at transferring momentum to $5 \mathrm{~mm}$ diameter ball bearings. The aspect ratio of 0.8 was one of the best for transferring momentum because the shape of the pressure front reaching the $5 \mathrm{~mm}$ ball bearing meant that there was a slightly higher pressure behind the ball bearing located at the radial centre than the pressure at the radial edges of the charge. Figure 14 shows the simulated pressure contour plots from the $27.16 \mathrm{~g}$ detonation with a $10 \mathrm{~mm}$ ball bearing. The detonation front propagating through the explosive charge length was curved (Figure 14a), with its peak pressure at the radial centre, well-aligned with the bearing location (Figure 14b). This explains the efficient momentum transfer to the bearings that occurred between $2 \mu \mathrm{s}$ and $6 \mu \mathrm{s}$, according to Figure $5 \mathrm{~b}$, as the pressure accumulation behind the ball bearing accelerated the bearing and caused a compressive hydrostatic pressure wave within the bearing itself.

Figure 14c shows the pressure distribution within the explosive charge after $2.99 \mu \mathrm{s}$. While the pressure interacting with the bearing was still high, the maximum pressures were observed on the charge face away from the radial centre, with the detonation wave moving past the ball bearing in the other sections of the charge. This interrupted detonation front is responsible for the pressure wave that moves ahead of the ball bearing. The diameter of the ball bearing determines how much of the detonation front interacts with the ball bearing (imparting momentum to it) and how much moves past, contributing directly to the blast pressure moving ahead of the bearing. Thus, heavier ball bearings with larger charge diameters require more momentum to import high peak velocities, but they also interact with a larger portion of the explosive charge because of their higher surface area.

This explains why the decreases in peak velocities of the heavier bearings were not far lower. It also explains why the reflected blast pressures did not cause larger percentage drops in the bearing speed for the same charge mass and shape-firstly, the momentum was higher, requiring greater pressures to decelerate the bearings, and secondly, less of the charge mass directly contributed to the reflected pressure front due to the increased 
bearing surface area (decreasing the surface area over which the opposing blast pressure acts). When charge mass and shape are varied, there are additional factors to consider, such as the influence of aspect ratio on the efficiency of momentum transfer to the bearing itself (see [8]) and that larger charge masses increase the reflected blast pressures, causing the bearing velocity to decrease more rapidly.

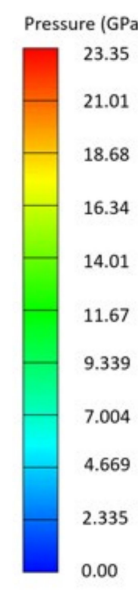

(a)

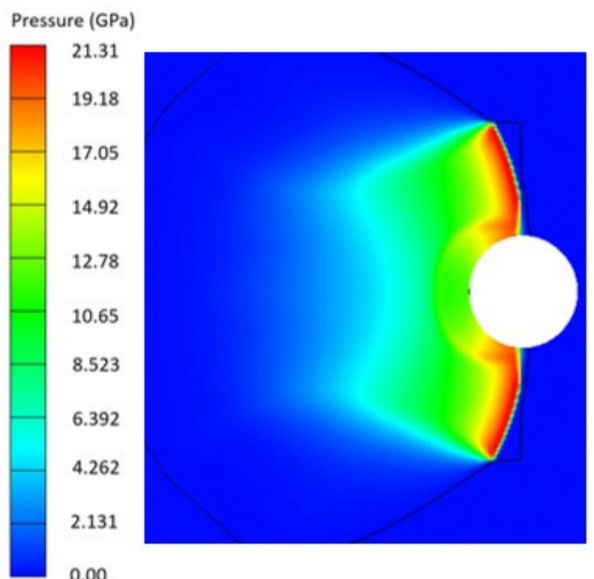

(c)

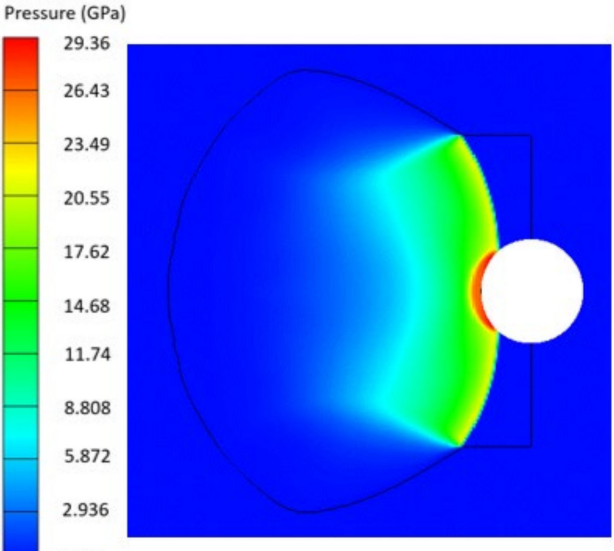

(b)

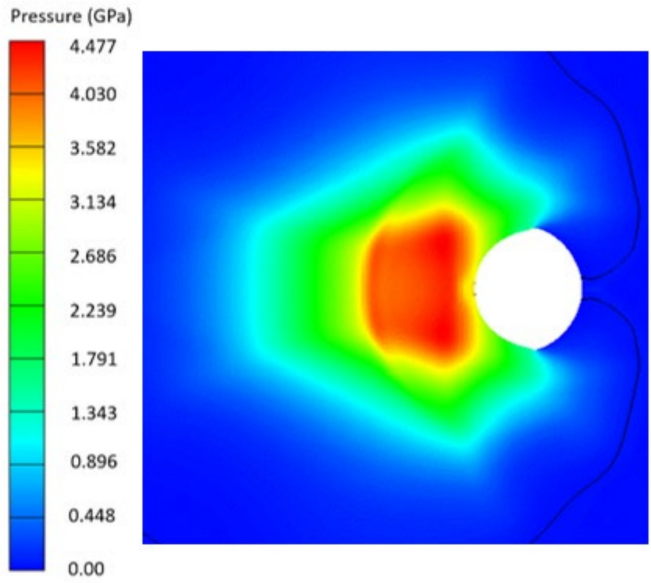

(d)

Figure 14. Simulated pressure contour plots from detonating a $27.16 \mathrm{~g}$ charge (30 mm diameter) embedded with a $10 \mathrm{~mm}$ diameter ball bearing at (a) $1.8 \mu \mathrm{s}$, (b) $2.55 \mu \mathrm{s}$, (c) $2.99 \mu \mathrm{s}$, (d) $4.53 \mu \mathrm{s}$.

\section{Concluding Remarks}

The new simulations were satisfactorily validated using experimental work and a previously validated modelling approach [17]. The peak bearing velocity were not influenced by the improved bearing damage model of the finer bearing mesh. This confirmed that momentum transfer is mainly influenced by the charge mass to ball bearing mass ratio and the aspect ratio of the charge. Larger ball bearings require extra momentum to accelerate them to higher velocities due to their increased mass, but their higher surface area also means that a greater portion of the explosive charge is involved in momentum transfer. The drop in velocity observed part-way through the bearing flight due to interaction with the reflected pressure was influenced by bearing diameter charge diameter. Higher momentum required greater reflected pressures to decelerate the bearing, but the reflected pressure acted over a larger surface area. Additionally, less of the charge mass directly contributed to the reflected pressure front in low diameter charges; this was due to the increased bearing surface area meaning that less of the blast pressure moved past the ball bearing in the early stages of blast wave formation. 
Using a post-test damage analysis and an enhanced ball bearing modelling approach, tensile spalling was found to be the major damage mechanism within the ball bearings. The charge aspect ratio affected the initial compressive hydrostatic pressure propagation within the ball bearing itself; the compressive stress was then reflected from the free surface of the bearing as a tensile wave. The focusing effect due to bearing curvature and charge geometry influenced the magnitude and shape of the tensile spalling wave, affecting the location and degree of internal cracking within the bearings. In some cases, it may be possible to cause the bearing to break apart due to extensive internal cracking caused by tensile spalling. These findings will prove valuable to blast protection engineers considering the effects of embedded projectiles in improvised explosive devices, enabling projectile velocities and trajectories to be estimated for future injury estimates from IED events.

Author Contributions: Conceptualization, G.S.L. and T.J.C.; methodology, T.J.C., S.C.K.Y., G.S.L. and R.Q.; investigation, R.Q., G.S.L., T.J.C. and S.C.K.Y.; resources, G.S.L.; data curation, R.Q.; writing —original draft preparation, G.S.L. and R.Q.; writing—review and editing, T.J.C. and S.C.K.Y.; supervision, G.S.L. and T.J.C.; project administration, G.S.L.; funding acquisition, G.S.L. All authors have read and agreed to the published version of the manuscript.

Funding: This research was funded by the National Research Foundation (NRF) of South Africa, grant number 111737.

Institutional Review Board Statement: Not applicable.

Informed Consent Statement: Not applicable.

Data Availability Statement: The data presented in this study are available on request from the corresponding author.

Acknowledgments: The authors are grateful to the National Research Foundation (NRF) of South Africa for their financial support. Opinions expressed and conclusions arrived at are those of the authors and are not necessarily attributable to the NRF. The authors would also like to thank the staff of the Mechanical Engineering workshop at UCT for their assistance in machining the specimens and pendulum parts.

Conflicts of Interest: The authors declare no conflict of interest.

\section{References}

1. Overton, I. A Decade of Global IED Harm Reviewed; Action on Armed Violence: London, UK. 2020. Available online: https: / / aoav.org.uk/2020/a-decade-of-global-ied-harm-reviewed/ (accessed on 25 November 2021).

2. Smith, S.; Devine, M.; Taddeo, J.; McAlister, V.C. Injury profile suffered by targets of antipersonnel improvised explosive devices: Prospective cohort study. BMJ Open 2017, 7, e014697. [CrossRef] [PubMed]

3. Singleton, J.A.G.; Gibb, I.E.; Hunt, N.C.A.; Bull, A.M.J.; Clasper, J.C. Identifying future 'unexpected' survivors: A retrospective cohort study of fatal injury patterns in victims of improvised explosive devices. BMJ Open 2013, 3, e0031302013. [CrossRef] [PubMed]

4. Diaz, D.; Hahn, D.W. Raman spectroscopy for detection of ammonium nitrate as an explosive precursor used in improvised explosive devices. Spectrochim. Acta Part A Mol. Biomol. Spectrosc. 2020, 233, 118204. [CrossRef] [PubMed]

5. Zapata, F.; de la Ossa, M.Á.F.; Gilchrist, E.; Barron, L.; García-Ruiz, C. Progressing the analysis of Improvised Explosive Devices: Comparative study for trace detection of explosive residues in handprints by Raman spectroscopy and liquid chromatography. Talanta 2016, 161, 219-227. [CrossRef] [PubMed]

6. Mileusnic, M.; Petrovic, P.; Pavic, B.; Merinkovic-Nedelicki, V.; Glisovic, J.; Lebl, A.; Marjanovic, I. The radio jammer remote controlled improvised explosive devices. In Proceedings of the 25th Telecommunications Forum TELFOR, Belgrade, Serbia, 21-22 November 2017.

7. Wilson, C. Improvised explosive devices in Iraq and Afghanistan: Effects and countermeasures. In Proceedings of the Library of Congress Washington DC Congressional Research Service, Washington, DC, USA, 2 November 2007.

8. Kamel, H. Review of design techniques of armored vehicles for protection against blast from Improvised Explosive Devices. In Proceedings of the ASME 2019 International Mechanical Engineering Congress and Exposition, Salt Lake City, UT, USA, 8-14 November 2019.

9. Landucci, G.; Reniers, G.; Cozzani, V.; Salzano, E. Vulnerability of industrial facilities to attacks with improvised explosive devices aimed at triggering domino scenarios. Reliab. Eng. Syst. Saf. 2015, 143, 53-62. [CrossRef]

10. Vanderheyden, N.; Verhoeven, E.; Vermeulen, S.; Bekaert, B. Survival of forensic trace evidence on improvised explosive devices: Perspectives on individualisation. Sci. Rep. 2020, 10, 12813. [CrossRef] [PubMed] 
11. Gurney, R.W. The Initial Velocities of Fragments from Bombs, Shell and Grenades; Technical Report; Army Ballistic Research Lab Aberdeen Proving Ground Md: Dayton, OH, USA, 1943. Available online: https://apps.dtic.mil/sti/pdfs/ADA800105.pdf (accessed on 20 December 2021).

12. Balden, V.; Nurick, G. Numerical simulation of the post-failure motion of steel plates subjected to blast loading. Int. J. Impact. Eng. 2005, 32, 14-34. [CrossRef]

13. Zhang, Q.; Miao, C.Q.; Lin, D.C.; Bai, C.H. Relation of fragment with air shock wave intensity for explosion in a shell. Int. J. Impact. Eng. 2003, 28, 1129-1141. [CrossRef]

14. Choudha, P.K.; Kumaraswamy, A.; Dhote, K.D. Parametric study of single confined fragment launch explosive device. Defence Tech. 2018, 15, 179-185. [CrossRef]

15. Kennedy, J. Gurney Energy of Explosives: Estimation of The Velocity and Impulse Imparted to Driven Metal; Technical Report; Sandia Laboratories: Livermore, CA, USA, December 1970.

16. Kang, G.; Yuen, S.C.K. Response of a structural target to an explosive charge incorporating foreign objects. In Proceedings of the 7th International Conference Structural Engineering, Mechanics, and Computation (SEMC), Cape Town, South Africa, 2-4 September 2019.

17. Qi, R.; Langdon, G.S.; Cloete, T.J.; Chung Kim Yuen, S. Behaviour of a blast-driven ball bearing embedded in rear detonated cylindrical explosive. Int. J. Impact. Eng. 2020, 146, 103698. [CrossRef]

18. Stoner, R.G.; Bleakney, W. The Attenuation of Spherical Shock Waves in Air. J. Appl. Phys. 1948, 19, 670-678. [CrossRef]

19. Xiao, W.; Andrae, M.; Gebbeken, N. Effect of charge shape and initiation configuration of explosive cylinders detonating in free air on blast-resistant design. J. Struct. Eng. 2020, 146, 04020146. [CrossRef]

20. Qi, R.; Langdon, G.S.; Cloete, T.J.; Chung Kim Yuen, S. Deformation and damage characteristics of ball bearings under blast loading. In Proceedings of the 13th International Conference on the Mechanical and Physical Behaviour of Materials under Dynamic Loading, Madrid, Spain, 20-24 September 2021; Volume 250, p. 05008. [CrossRef]

21. DIN 50150:1976; Testing of Steel and Cast Steel; Conversion Table for Vickers Hardness, Brinell Hardness, Rockwell Hardness and Tensile Strength. Beuth Verlag GmBH: Berlin, Germany, 1976.

22. Pavlina, E.J.; Van Tyne, C.J. Correlation of yield strength and tensile strength with hardness for steels. J. Mater. Eng. Perform. 2008, 17, 888-893. [CrossRef]

23. Qi, R. The Influence of Cylindrical Charge Geometry on the Velocity of Blast-Driven Projectiles in One Dimension. Master's Thesis, University of Cape Town, Cape Town, South Africa, 2020.

24. Davids, S.A.; Langdon, G.S.; Nurick, G.N. The influence of charge geometry on the response of partially confined right circular stainless steel cylinders subjected to blast loading. Int. J. Impact. Eng. 2017, 108, 252-262. [CrossRef]

25. Yuen, S.C.K.; Butler, A.; Bornstein, H.; Cholet, A. The influence of orientation of blast loading on quadrangular plates. Thin-Walled Struct. 2018, 131, 827-837. [CrossRef]

26. Lee, J.; Hornig, E.L.; Kury, H.C. Adiabatic Expansion of High Explosive; Technical Report; Lawrence Livermore: Livermore, CA, USA, 1968. [CrossRef]

27. Johnson, G.R.; Cook, W.H. A constitutive model and data for materials subjected to large strains, high strain rates, and high temperatures. In Proceedings of the 7th International Symposium on Ballistics, The Hague, The Netherlands, 19-21 April 1983; pp. 541-547.

28. Peng, Y.; Wang, G.; Zhu, T.; Pan, S.; Rong, Y. Dynamic mechanical behaviors of 6082-T6 aluminum alloy. Adv. Mech. Eng. 2013, 878016. [CrossRef]

29. Zhang, L.; Li, P.; Tang, S.; Tang, W.; Zhang, S. Mechanical behaviors analysis and Johnson-Cook model establishment of 4 Cr13 Stainless Steel. Key Eng. Mater. 2013, 589-590, 45-51. [CrossRef] 